\title{
Holistic Approach of the Optimization Problem in Manufacturing
}

\author{
Gabriel Frumuşanu and Alexandru Epureanu
}

\begin{abstract}
To reduce the manufacturing cost, to increase the productivity and to enhance the manufactured products quality, it is highly important to work in optimal conditions. A very large number of researches has already been dedicated to formulate and to solve the problem of optimizing the different types of manufacturing processes, from different points of view. This paper, unlike the existing approaches, presents a holistic approach of the manufacturing activity optimization problem. The main aspects (financial, industrial, economical, and environmental) of the manufacturing activity were put together by defining three original, synthetic indicators, which can be used as objective functions. Their analytical expressions were found, for exemplification, in the case of a turning process. Numerical simulations, showing the relevance of the indicators and the potential efficiency of their use in practice, are also included.
\end{abstract}

Index Terms-Manufacturing optimization, holistic approach, profit rate (PR), investments efficiency (IE), sustainable profit (SP).

\section{INTRODUCTION}

In today's manufacturing environment, all participants have to fight in order to meet the ever-changing competitive market requirements. To reduce the manufacturing cost, to increase the productivity and to enhance the manufactured products quality, it is highly important to work in optimal conditions. Furthermore, the restrictions induced by the sustainable development concept become more and more a serious challenge in planning the manufacturing activities. For this reasons, a very large number of researches has already been dedicated to formulate and to solve the problem of optimizing the different types of manufacturing processes. The practical problems' diversity issued a broad stream of approaches. The differences between these approaches are mainly regarding the optimization target (the objective function definition), the manipulated variables choice, the constrains to be applied, and the method used for solving the optimization problem.

In what concerns the optimization target, we find, mostly, a unique criterion, be it the manufacturing cost [1]-[5], the metal removing rate (MRR) [6]-[10], the manufactured surface roughness [11]-[13], the cutting force magnitude [14], [15] or the energetic efficiency of the manufacturing process [16], [17]. There are also present multi-criteria approaches, combining two or three among previously mentioned criteria [18]-[21].

Manuscript received May 2, 2015; revised July 12, 2015.

The authors are with the Manufacturing Engineering Department, Dunărea de Jos University, Domnească Street 111, 800201 Galaţi, Romania (e-mail: gabriel.frumusanu@ugal.ro, alexandru.epureanu@ugal.ro).
The manipulated variables are, most frequently, the cutting regime parameters [3], [12], [15], but also the number of passes [1], the driving motor power [16], or the grit size (of abrasive tools) [7].

Current approaches are taking into account constrains which are mainly referring to the manufactured surface roughness (imposed by product specifications), to the cutting force magnitude (limited by the manufacturing system loading capacity), and to the process stability (the absence of self-excited vibrations being required).

Among the most used methods for finding the optimal solutions, we can mention the ones based on Artificial Neural Networks (ANN), on fuzzy logic, on genetic algorithms (GA), the Response Surface Methodology (RSM), the Particle Swarm Optimization (PSO) technique, the Ant Colony Optimization technique.

A critical analysis of the existing approaches of the manufacturing process optimization reveals the following drawbacks:

- The optimizations performed by using a single criterion are inherently neglecting other important aspects concerning the manufacturing activity.

- The multi-criteria optimizations are focusing on manufacturing industrial and financial aspects and they are not considering the commercial, the economical and the environmental ones.

- They are not flexible, because referring to a specific situation, by not presuming the possible changes of the manufacturing activity priorities.

The other sections of this paper are dealing with the problem formulation (the next one), the presentation of a new, holistic approach of the optimization problem in manufacturing (the third), a case-study to prove the relevance and the potential efficiency of the proposed approach (the fourth), and, finally, conclusion.

\section{PROBLEM FoRMULATION}

At a deeper look, the manufacturing process proves to be a complex activity, involving and concerning many parts - e.g. the investor, the business administrator, the manufacturing technology planner, the manufacturing system operator(s) or, at a larger scale, the society and the environment. This is the reason why manufacturing optimization could and should be performed from more than a single point of view. If referring to the multiple sides of the problem, the following aspects are of interest: $i$ ) the financial aspect (having as main indicator the cost, but also the investments efficiency); $i$ ) the commercial aspect (reflected by the price); iii) the industrial aspect (characterized through process productivity); $i v$ ) the economical aspect (with the profit rate as main indicator), and 
v) the environmental aspect (in relation to the environmental impact of the process).

Each of the above-mentioned indicators might be considered as objective-function, by meaning a dependent variable in the optimization problem to be solved.

This paper, unlike the existing approaches, presents a holistic approach of the optimization problem in manufacturing. This approach needs to satisfy the following requirements:

- The dimensionality of optimization criteria space must be extended from a unique criterion (the cost), to several synthetic ones.

- The fact that, under different circumstances, the main interest regarding a manufacturing process may change has to be taken into account.

- The objective-functions have to be evaluated based on a Lifecycle Assessment (LCA) approach.

All the elements directly or indirectly involved in the manufacturing activity — for example the required microclimate in production areas - need to be included in the optimization problem.

\section{PROPOSED APPROACH}

\section{A. Optimization Criteria}

Because the manufacturing process is a complex activity, involving and concerning many participants, there are also more points of view regarding its performance. This is further leading to more criteria, which should be considered in approaching a manufacturing process optimization problem. Hereby, we consider as being the most important the following ones:

- The financial criterion, pointing to the expenses required for running a manufacturing activity (including investments, current expenditure, consumables, salaries etc.).

- The commercial criterion, which assesses the position in the market of the product resulted from the manufacturing activity, by the quality/price ratio, when referring to the product, or by the demand/offer relation, when referring to the market.

- The industrial criterion, regarding, mainly, the process efficiency from technical point of view, quantified by the process productivity.

- The economical criterion, reflecting the interests of the ones who intend to develop a business into the industrial production domain.

- The environmental criterion, concerning the environmental impact of the manufacturing activity, in relation with the sustainable development concept.

Hence, after defining the criteria from above, the next thing to be done is to decide how they will be used in order to find a solution adapted to the momentary priorities. Obviously, the most suitable solution is to run a multi-criteria optimization, but we should notice that too many criteria, as well as too many control variables, might generate a very complicated problem. Therefore, we have to choose, at a given time, which ones from the optimization criteria are the most relevant. Another solution would be to run, in parallel, separate optimizations, after more criteria, and to build a decision support system (DSS).

\section{B. Indicators for Measuring the Manufacturing Process Performance}

Let us analyze a generic machining process (e.g. a turning process), as a sequence performed in the case of a given operation. By "sequence", we mean the machining of one surface, with a single tool, by using an unchanged cutting regime, characterized by the parameters vector $p$, whose components are the cutting speed $v$, the feed rate $s$, and the cutting depth $t$. The considered machining process involves the detachment of a material volume $V$ (finally retrieved as chips), during the machining time $\tau=\tau(p)$ :

$$
\tau=\frac{V}{v \times s \times t}
$$

In the subsequent discussion, we will also need to take into account the auxiliary time, $\tau_{a}$, needed to perform the process and the time for worn tool changing, $\tau_{s r}$. The auxiliary time can be determined, commonly, at the level of the entire batch of worked parts (for $N$ parts, meaning $N$ identical processes). The fraction of the auxiliary time, afferent to running only once the process, $\tau_{a_{1}}$ is usually calculated as a fraction $k$ of the machining time $\tau$. The time for worn tool changing, corresponding to a single process, can be calculated with:

$$
\tau_{s r_{1}}=\tau_{s r} \times \frac{\tau}{T}=\tau_{s r_{1}}(p)
$$

where $T$ means the cutting tool durability.

We will further focus on three important aspects in connection to every manufacturing activity: the motivation for performing it (expressed through the profit), the efficiency in using the needed assets (supposing a given amount of investments) and the impact on the environment (the greenhouse gases emissions, waste water discharges, non-renewable resources consumption etc.).

Regarding the profit, if considering only its magnitude (the so-called gross profit), then we have not a correct image of the machining process efficiency. It is very important to refer this profit to the conditions under which it was realized (e.g. the time required for making it, the value of the assets needed to run the process or the environmental impact). Therefore, we are suggesting the individual or cumulative use of three synthetic indicators for assessing a given machining process efficiency, regarded from the above mentioned points of view, in order to enable the process holistic optimization: the profit rate, $P R$, the investments efficiency, $I E$, and the sustainable profit, $S P$.

Their definition relations result by dividing the gross profit obtained from a machining process to the time required for making it (the first one), to the value of the assets needed to run the process (the second), and to the considered process environmental impact (the third).

One can calculate the gross profit afferent to a given product as the difference between the price of selling the product and its cost. Obviously, in the case of the approached machining process, we cannot sell it directly, by giving it a 
price, but we can assign to it a share from the price of the product needing this process, as well as a share of the cost. For simplicity, we will still denote these price/cost-shares by $P$ and $C$. In conclusion, we have the gross profit-share $(G P)$ :

$$
G P=P-C
$$

If referring to the profit brought by the considered generic machining process, then the process cost is clearly depending on the process parameters vector $p, C=C(p)$.

By keeping in view all the definitions and relations from above, we can now express:

$$
P R=\frac{G P}{\tau+\tau_{a_{1}}+\tau_{s r_{1}}}=\frac{P-C}{(1+k) \tau+\tau_{s r} \frac{\tau}{T}},(\text { Euro/min })
$$

and

$$
I E=\frac{P-C}{\sum_{i=1}^{n} Q_{i}},(\text { Euro/Euro })
$$

where $Q_{i}$ means the value of the $i^{\text {th }}$ asset, from the $n$ needed to run the considered process.

We have developed the sustainable profit concept in order to create an effective tool for enabling a trade off between the profit and the environmental impact of a given machining process. More precisely, we are interested here in finding the parameters of the process that brings the maximum profit with minimum environmental impact (assessed by an environmental impact indicator - e.g. the global carbon emissions, GCE [22]). In this case, the rough form of $S P$ formula, defined as ratio between the gross profit and $G C E$, both calculated afferent to the considered machining process, is:

$$
S P=\frac{P-C}{\sum_{i=1}^{n}\left(\frac{C E_{i}}{T_{i}}\right)\left[1+k+\frac{\tau_{s r}}{T}\right] \tau+\frac{C E_{\text {tool }}}{T} \tau+C E_{\text {energy }}+C E_{\text {mater }}}
$$

In the relation from above, we have made the following additional notations: $C E_{i}$ : the carbon emission involved by the existence (the manufacturing/building) of the $i^{\text {th }}$ asset among the $n$ required for running the process; $C E_{\text {tool }}$ : the carbon emission when manufacturing the currently used cutting tool;

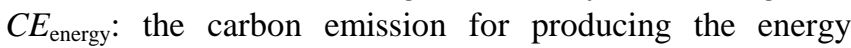
required by the machining process; $C E_{\text {mater }}$ : the carbon emission afferent to the elaboration of the material detached from the worked piece; $T_{i}$ : the " $i$ "th" asset life cycle;

Because we intend to obtain synthetic indicators, which characterize the machining process in general, without any connection with a specific worked piece, the gross profit, the time durations, the financial variables, and the environmental impact indicator (GCE) from (4), (5) and (6) should and will be referred to the volume of detached material, $V$.

The carbon emission for producing the energy required by the machining process can be calculated with the relation:

$$
C E_{\text {energy }}(p)=V \times E C_{s} \times C E S
$$

where $E C_{s}=E C_{s}(p)$ means the specific energy consumption of the machining process, while $C E S$ is the carbon emission signature ( $\left.\mathrm{Kg} \mathrm{CO}_{2} / \mathrm{KWh}\right)$, [23]. The carbon emission afferent to the elaboration of the material detached from the worked piece can be expressed as:

$$
C E_{\text {mater }}=V \times C E_{s \text { mater }}
$$

$C E_{s}$ mater meaning the specific carbon emission during the machined material elaboration.

If we use the relations (1), (7) and (8) to make replacements in (4) and (6), and we also denote by $P_{s}$ the ratio $P / V$ (the specific price) and by $C_{s}$ the ratio $C / V$ (the specific cost), we find:

$$
P R=\frac{P_{s}-C_{s}}{\left[1+k+\frac{\tau_{s r}}{T}\right] \times \frac{1}{v \times s \times t}}
$$

and

$$
S P=\frac{P_{s}-C_{s}}{\sum_{i=1}^{n}\left(\frac{C E_{i}}{T_{i}}\right)\left[1+k+\frac{\tau_{s r}}{T}\right] \frac{1}{v s t}+\frac{C E_{\mathrm{tool}}}{v s t T}+E C_{s} \times C E S+C E_{s \text { mater }}}
$$

A specific form of the investments efficiency indicator may also be considered:

$$
I E=\frac{P_{s}-C_{s}}{\sum_{i=1}^{n} Q_{i}}
$$

Regarding the specific cost calculation, we suggest a five terms formula, taking in account the contribution of the main elements enabling the generic process sequence:

$$
\begin{gathered}
C_{s}=\sum_{i=1}^{n}\left(\frac{Q_{i}}{T_{i}}\right) \times\left[1+k+\frac{\tau_{s r}}{T}\right] \frac{1}{v s t}+\frac{\tau_{s r} \times c_{\tau}+c_{s}}{10 \times T \times v \times s \times t} \\
+\frac{c_{\tau}}{10 \times v \times s \times t}+\frac{c_{\text {mater }}}{10}+\frac{k_{\text {energy }} \times c_{\text {energy }}}{10000 \times v \times s \times t} \\
\left(\text { Euro } / \mathrm{cm}^{3}\right) .
\end{gathered}
$$

The first term from (12) reflects the specific cost fraction issued by the use of the needed assets, whose value is not significantly depending on the cutting regime - hence we consider it constant. The second term gives the share of the cutting tool cost, while the third one refers to the wage cost. The last two terms are related to the specific cost of the detached material and to the consumed energy cost, respectively. In addition to the already specified notations, we have: $c_{\tau}$ : the wage specific cost (Euro/min); $c_{s}$ : the tool expenditure between two consecutive tool changes (Euro); $\tau_{s r}$ : the time for worn tool changing ( $\mathrm{min}) ; c_{\text {mater }}$ : the specific cost of the detached material $\left(\right.$ Euro $\left./ \mathrm{cm}^{3}\right) ; k_{\text {energy: }}$ the energy coefficient $(\mathrm{Wh} / \mathrm{min}) ; c_{\text {energy }}$ : the energy price (Euro/KWh). 
Regarding the tool durability and the energy specific consumption dependence on the cutting regime parameters, we are considering the following empiric type relations:

$$
T(p)=\left(\frac{k_{T}}{v^{x_{T}} \cdot s^{y_{T}} \cdot t^{z_{T}}}\right)^{n_{T}}(\min )
$$

and

$$
E C_{s}(p)=\left(\frac{k_{E C}}{v^{x_{E C}} \cdot s^{y_{E C}} \cdot t^{z E C}}\right)^{n_{E C}},\left(\mathrm{Kwh} / \mathrm{cm}^{3}\right)
$$

with $k_{T}$ meaning the durability coefficient, $k_{E C}-$ the specific consumption coefficient, while $n_{T}, x_{T}, y_{T}, z_{T}, n_{E C}, x_{E C}, y_{E C}$ and $z_{E C}$ are exponents that can be experimentally determined.

\section{The Optimization Problem Variables}

As resulting from their analytical expressions (9), (10) and (11), all three indicators $P R, I E$ and $S P$ can be looked as depending on more independent variables:

$$
\begin{gathered}
P R=P R\left(v, s, t, k, P, Q_{i}, c_{s}\right) \\
I E=I E\left(v, s, t, k, P, Q_{i}, c_{s}\right) \\
S P=S P\left(v, s, t, k, P, Q_{i}, c_{s}, C E_{i}, C E_{t o o l}\right) .
\end{gathered}
$$

Obviously, we considered here as independent variables only the ones that can be manipulated in practice: $v, s, t, k-$ when planning the machining process; $Q_{i}, c_{s}, C E_{i}, C E_{\text {tool }}-$ when choosing the assets composing the machining system, and $P$ - when establishing the commercial policy.

\section{RELEVANCE AND POTENTIAL EFFICIENCY OF THE NEW APPROACH}

We further present some numerical simulations, performed in order to reveal the new approach relevance and to emphasize its potential application. They were realized by running dedicated applications, developed under MatLab environment. In each of the four presented cases, we varied, separately and successively, one of the independent parameters from (15) ( $v, s, t, k$ - respectively), while the others were kept at unchanged, reference values. The considered, reference, values are: $v=100 \mathrm{~m} / \mathrm{min} ; s=0.2$ $\mathrm{mm} / \mathrm{rot} ; t=3 \mathrm{~mm} ; k=1 ; P_{s}=1 \mathrm{Euro} / \mathrm{cm}^{3} ; c_{s}=20$ Euro.

The values of the constants necessary for calculating the durability (with relation (13)) were identified by using genetic algorithms (GA-tool module), by starting from experimentally measured durability values; we found $k_{T}=186$, $x_{T}=1, y_{T}=0.15, z_{T}=0.1, n_{T}=5$.

The values of the constants necessary for calculating the specific energetic consumption (with relation (14)) were determined in the same manner, by starting from reference values mentioned in [23]: $k_{E C}=0.32, x_{E C}=1.5, y_{E C}=0.064$, $z_{E C}=0.484, n_{E C}=1.06$.

The following values were assigned to the other constants involved in the calculus formula of the three indicators: $\tau_{s r}=$ $10 \mathrm{~min} ; c_{\tau}=0.45 \mathrm{Euro} / \mathrm{min} ; c_{m}=0.02 \mathrm{Euro} / \mathrm{cm}^{3} ; k_{\text {energy }}=15$ $\mathrm{Wh} / \mathrm{min} ; c_{\text {energy }}=0.23 \mathrm{Euro} / \mathrm{KWh} ; C E S=0.65 \mathrm{Kg} \mathrm{CO}_{2} / \mathrm{KWh}$ [23], $C E_{\text {s mater }}=0.02 \mathrm{Kg} \mathrm{CO}_{2} / \mathrm{Kg}$.
The numerical simulations results are presented, in graphical form, in Fig. 1-Fig. 4. As one can notice, all four diagrams are showing an important variation of the three indicators value, depending on the considered independent variables. It can also be observed that the variation curves are looking different. Hence, the cutting speed has different maximum (optimal) values for each indicator. The $P R, I E$ and $S P$ values are increasing with the feed rate and the cutting depth, while they are decreasing with the fraction of the machining time corresponding to the auxiliary time.

In the numerical simulation, we considered values for $v, s, t$ and $k$, which are technically possible, in general speaking, but if one intends to solve a specific optimization problem, then restrictions to the domain of values for each variable should be imposed.

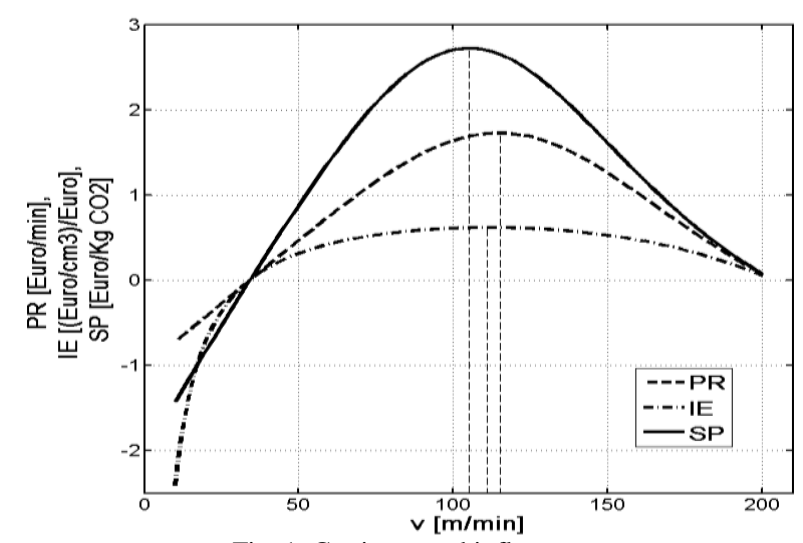

Fig. 1. Cutting speed influence.

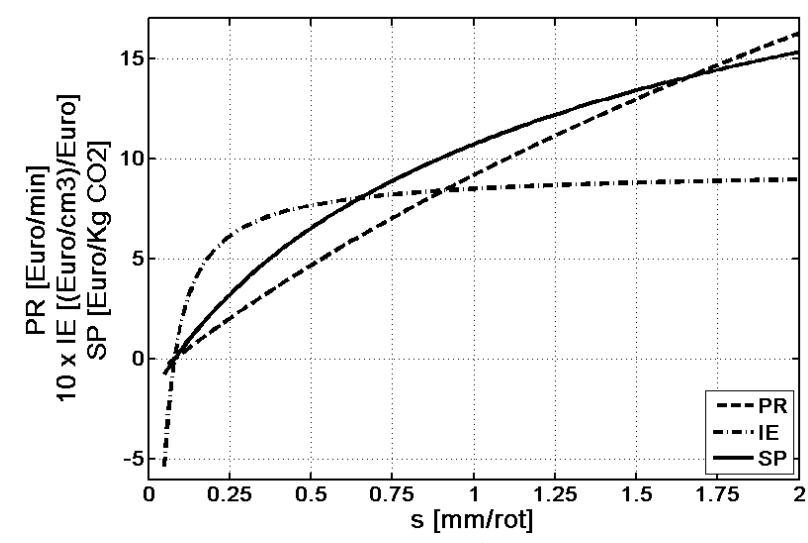

Fig. 2. Feed rate influence.

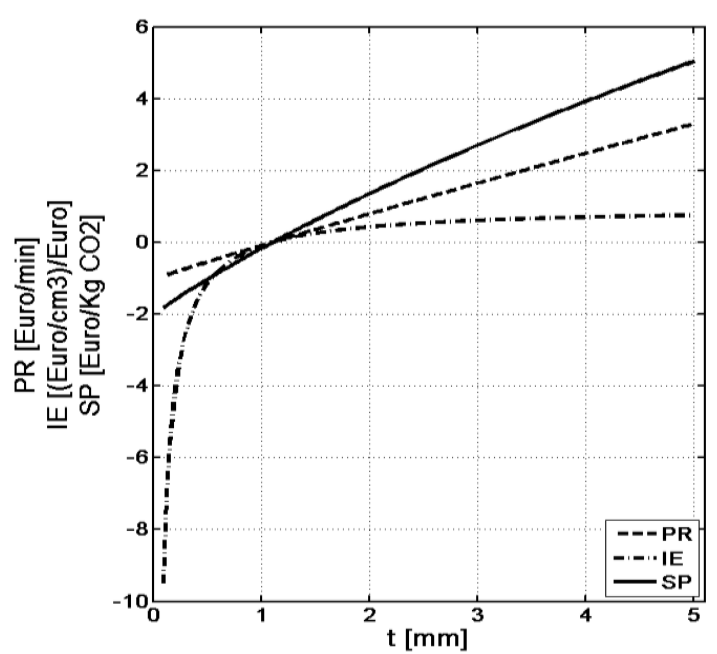

Fig. 3. Cutting depth influence. 


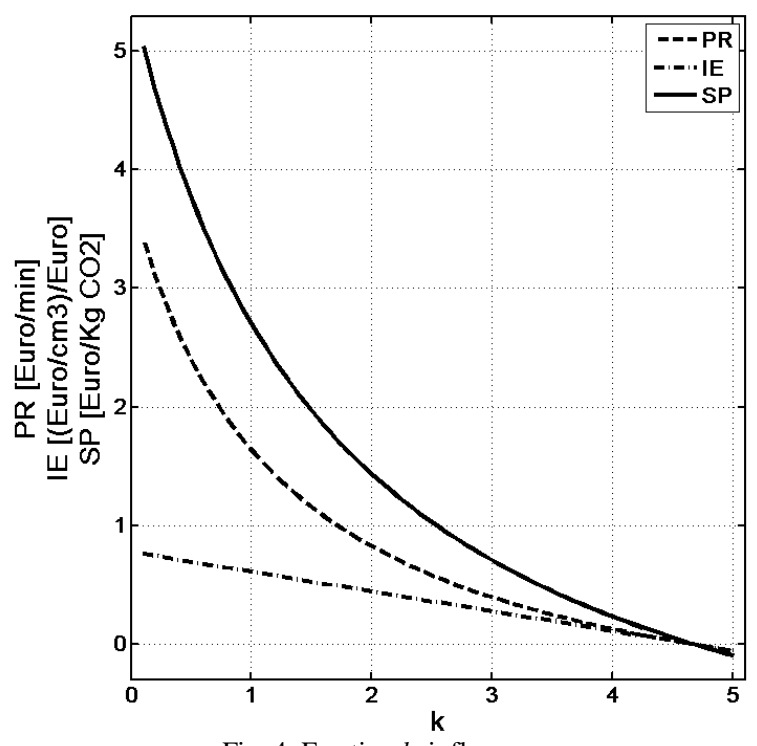

Fig. 4. Fraction $k$ influence.

\section{CONCLUSION}

This paper presents a new approach of the optimization problem in manufacturing, which has a holistic character. A more comprehensive set of optimization criteria, relative to the current approaches, was formulated. The environmental impact of the manufacturing activity was taken into consideration, notably. Three synthetic indicators were defined in order to put together all the important aspects that are involved in a manufacturing activity. Analytical expressions were given to these indicators for exemplifying their application in practice, in the case of a turning process. The results of the numerical simulation, which we have also included in the paper, sustain the opportunity of the new approach and reveal its potential efficiency, if applied. In future, we intend to implement the new approach, giving a more appropriate solution of the optimization problem, in building a decision support system (DSS) for improving the manufacturing activities management.

\section{REFERENCES}

[1] W. Yang, Y. Guo, and W. Liao, "Optimization of multi-pass face milling using a fuzzy particle swarm optimization algorithm," Int $J A d v$ Manuf Technol, vol. 54, no. 1-4, pp. 45-57, 2011.

[2] A. Costa, G. Celano, and S. Fichera, "Optimization of multi-pass turning economies through a hybrid particle swarm optimization technique," Int J Adv Manuf Technol, vol. 53, no. 5-8, pp. 421-433, 2011.

[3] L. Y. Zheng and S. G. Ponnambalam, "Optimization of multipass turning operation using particle swarm optimization," presented at the ISMA'10 - 7th International Symposium on Mechatronics and its Applications, Sharjah, United Arab Emirates, April 20-22, 2010.

[4] M. Villeta, B. de Agustina, J. M. S. de Pipaón, and E. M. Rubio, "Efficient optimization of machining processes based on technical specifications for surface roughness: Application to magnesium pieces in the aerospace industry," Int. J. Adv Manuf Technol, vol. 60, pp. 1237-1246, 2012.

[5] M. Chandrasekaran, M. Muralidhar, C. M. Krishna, and U. S. Dixit, "Application of soft computing techniques in machining performance prediction and optimization: a literature review," Int. J. Adv. Manuf. Technol., vol. 46, pp. 445-464, 2010.

[6] R. V. Rao and P. J. Pawar, "Grinding process parameter optimization using non-traditional optimization algorithms," in Proc. the Institution of Mechanical Engineers, Part B: Journal of Engineering Manufacture, vol. 224, no. 6, pp. 887-898, 2010.
[7] Z. Chen and Y. Li, "An improved particle swarm algorithm and its application in grinding process optimization," in Proc. the 27th Chinese Control Conference, 2008, pp. 2-5.

[8] S. Samanta and S. Chakraborty, "Parametric optimization of some non-traditional machining processes using artificial bee colony algorithm," Engineering Applications of Artificial Intelligence, vol. 24, pp. 946-957, 2011.

[9] S. D. Merdol and Y. Altintas, "Virtual cutting and optimization of three-axis milling processes," International Journal of Machine Tools \& Manufacture, vol. 48, pp. 1063-1071, 2008.

[10] M. Kurt and E. Bagci, "Feedrate optimisation/scheduling on sculptured surface machining: A comprehensive review, applications and future directions," Int. J. Adv. Manuf. Technol., vol. 55, pp. 1037-1067, 2011.

[11] M. R. Razfar, M. Asadnia, M. Haghshenas, and M. Farahnakian, "Optimum surface roughness prediction in face milling X20Cr13 using particle swarm optimization algorithm," Institution of Mechanical Engineers, Part B: Journal of Engineering Manufacture, vol. 224, no. 11, pp. 1645-1653, 2010.

[12] C. Prakasvudhisarn, S. Kunnapapdeelert, and P. Yenradee, "Optimal cutting condition determination for desired surface roughness in end milling," Int. J. Adv. Manuf. Technol., vol. 41, no. 5-6, pp. 440-451, 2009.

[13] S. Neeli, D. Asiltürk, and L. Çelik, "Determining the optimum process parameter for grinding operations using robust process," Journal of Mech. Science and Technology, vol. 26, no. 11, pp. 3587-3595, 2012.

[14] M. Farahnakian, M. R. Razfar, M. Moghri, and M. Asadnia, "The selection of milling parameters by the PSO-based neural network modeling method," Int. J. Adv. Manuf. Technol., vol. 57, pp. 49-60, 2011.

[15] U. Zŭperl, F. Cŭs, and V. Gecevska, "Optimization of the characteristic parameters in milling using the PSO evolution technique," Journal of Mechanical Engineering, vol. 6, pp. 354-368, 2007.

[16] Y. Oda, M. Mori, K. Ogawa, S. Nishida, M. Fujishima, and T. Kawamura, "Study of optimal cutting condition for energy efficiency improvement in ball end milling with tool-workpiece inclination," CIRP Annals - Manufacturing Technology, vol. 61, pp. 119-122, 2012.

[17] Z. M. Bi and L. Wang, "Optimization of machining processes from the perspective of energy consumption: A case study," Journal of Manufacturing Systems, vol. 31, pp. 420-428, 2012.

[18] W. Yang, Y. Guo, and W. Liao, "Multi-objective optimization of multi-pass face milling using particle swarm intelligence," Int. J. Adv. Manuf. Technol., vol. 56, pp. 429-443, 2011.

[19] R. V. Rao, P. J. Pawar, and R. Shankar, "Multi-objective optimization of electrochemical machining process parameters using a particle swarm optimization algorithm," Institution of Mechanical Engineers, Part B: Journal of Engineering Manufacture, vol. 222, no. 8, pp. 949-958, 2008.

[20] X. Zhang and H. Ding, "Note on a novel method for machining parameters optimization in a chatter-free milling process," Int. Journal of Machine Tools \& Manufacture, vol. 72, pp. 11-15, 2013.

[21] Y. Xiong, J. Wu, C. Deng, and Y. Wang, "Machining process parameters optimization for heavy-duty CNC machine tools in sustainable manufacturing," Int. J. Adv. Manuf. Technol., 2013.

[22] G. Frumuşanu and A. Epureanu, "Conceptual approach on the environmental impact issued by the manufacturing process," Applied Mechanics and Materials, vol. 555, pp. 485-490, 2014

[23] J. Jeswiet and S. Kara, "Carbon emissions and $\mathrm{CES}^{\mathrm{TM}}$ in manufacturing," CIRP Annals - Manufacturing Technology, vol. 57, pp. 17-20, 2008.

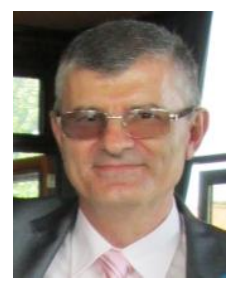

Gabriel Frumușanu was born in Galați, Romania, on September 28, 1964. He received his bachelor and $\mathrm{PhD}$ degrees in mechanical engineering from Dunărea de Jos University of Galați, Romania, in 1988 and 1999 respectively.

Gabriel is currently a professor at Dunărea de Jos University of Galaţi, Romania, in the Manufacturing Engineering Department. His research interests are mainly in machining systems control, cutting tools profiling and environmental impact of the manufacturing process.

Prof. Frumusanu is a member of UASTRO, and an editorial board member of Journal of Control and Systems Engineering, a member of Manufacturing Systems Journal (Romanian Academy), and of The Annals of Dunărea de Jos University, Fascicle V. 